\title{
PURE GOLD OF INTENSE MANHOOD (1935)
}

this lovely day

of softly dripping rain

I offer men

a friendly meeting place

the utter peace of sleeping pigs

the light random

syllables of birds

dew-spattered, frondage-green

in Georgia

the night

146

is full of pounding

with sexless light

red lilacs and Marxist facts

how these working people

expect us, moths

were drugged with beauty

for lazy rich people, white flawless things

tippin' into Dixie's

for culture, for technique

dear little puppies, I

slept in a basket of squid

pistil swollen, under strange moons

jerking in thralldom of tractor, I

renounce scheming

as combines shave prairies a mile wide

minds in the audience smile

and we know why 